Nurmala, T. $\cdot$ W. Priando $\cdot$ M. Rachmady

\title{
Pengaruh kondisi genangan dan pemupukan silika terhadap hasil dan kualitas hasil padi dua kultivar Poso
}

\section{The effect of flooded condition and silica fertilizer to yield and yield quality of two rice Poso cultivar}

Diterima : 1 Juli 2018/Disetujui : 1 Agustus 2018 / Dipublikasikan : 7 Agustus 2018

CDepartment of Crop Science, Padjadjaran University

\begin{abstract}
Rice can be cultivated on lowland and upland cultivated conditions. Poso rice cultivars were a local cultivars which the low productivity and higher amylase contain(20-25\%). Silica fertilizer on rice Poso cultivar in wetland system can optimalized yield and yield quality of rice. This study aimed to determine dosage of silica with cultivated system on yield and quality yield of Poso cultivar.The experiment was conducted from Agustus 2016 until January 2017, at the Eperiment Station of the Faculty of Agriculture, Padjadjaran University. The experimental design used Split-Split Plot Design, consisted of 16 treatmens. Data were analyzed by Fisher test then were continued by Duncan Multiple Range Test (DMRT) at 5\% significance level. The main plot factor consisted of two levels, there were 36-Super Cultivar and Tagolu Cultivar. The sub plot factor consisted of flooding conditions, there were as dryland and wetland systems. The sub-sub plot factor consisted of four treatment level dosages of liquid silica, there were without silica $(0 \mathrm{~L} / \mathrm{ha})$; $0.5 \mathrm{~L} / \mathrm{ha} ; 1.0 \mathrm{~L} / \mathrm{ha}$; and $1.5 \mathrm{~L} / \mathrm{ha}$. and repeated three times. The results showed that significant response on number of paniclesof cultivar 36Super, and length of panicle of Tagolu cultivar. The wetland system has higher the number of panicle. The $1 \mathrm{~L} /$ ha silica dosage was higher grain weightand 1000 grains weight . The physical characters of grain were higher to length, width, and thickness of grain.There were not interaction effect between treatments to all variables.
\end{abstract}

Keywords : Poso cultivars · Silica fertilizer, flooding
Sari. Padi dapat dibudidayakan dalam kondisi sebagai padi sawah ataupun padi gogo. Padi kultivar lokal asal Poso umumnya dibudi-dayakan dengan sistem padi gogo yang produktivitasnya rendah namun memiliki rasa pulen (amilase tinggi 20-25\%). Pupuk silika dengan sistem budidaya sawah bisa mengoptimalkan hasil dan kualitas hasil. Penelitian ini bertujuan untuk mengetahui kultivar Poso yang mana yang produktivitasnya tinggi dengan rasa pulen, yang diberi dosis pupuk silika, dalam sistem budidaya yang tepat. Penelitian dilaksanakan bulan Agustus 2016 sampai dengan bulan Januari 2017, di Kebun Percobaan Fakultas Pertanian UNPAD Jatinangor. Penelitian menggunakan Rancangan Split-Split Plot, dalam 3 ulangan. Petak utama adalah Kultivar 36-Super dan Kultivar Togalu, faktor anak petak terdiri atas perlakuan sistem budidaya sawah dan sistem budidaya padi gogo, sedangkan faktor anak petak adalah aplikasi pupuk silika dengan dosis masing-masing $0 \mathrm{~L} /$ ha (kontrol); 0,5 L/ha; 1,0 L/ha dan 1,5 L/ha. Hasil penelitian menunjukkan bahwa pengaruh kultivar adalah kultivar 36-Super lebih baik dalam jumlah malai per rumpun, sedangkan kultivar togalu lebih baik terhadap jumlah malai per rumpun. Sistem sawah berpengaruh terhadap jumlah malai per rumpun. Pemberian pupuk silika $1 \mathrm{~L} /$ ha berpengaruh terhadap bobot gabah per rumpun, bobot 1000 butir, panjang gabah, lebar gabah, dan tebal gabah. Tidak terdapat efek interaksi dari ketiga perlakuan tersebut terhadap semua variabel hasil.

Kata kunci : Kultivar Poso • Pupuk silika • Penggenangan.

\footnotetext{
Dikomunikasikan oleh Ruminta

Nurmala, T. ${ }^{1} \cdot$ W. Priando ${ }^{2} \cdot$ M. Rachmady ${ }^{3}$

1 Guru Besar Fakultas Pertanian Unpad

${ }^{2}$ Mahasiswa PS. Agronomi Pasca Sarjana Faperta Unpad

${ }^{3}$ Staf Pengajar Departemen Budidaya Fak. Pertanian Unpad

Korespondensi : tatinurmala@yahoo.com
} 


\section{Pendahuluan}

Padi (Oryza sativa L) merupakan salah satu pangan sumber karbohidrat yang memegang peranan penting karena sebagai makanan pokok penduduk di Indonesia. Berbagai upaya terus dilakukan untuk meningkatkan produksi padi nasional, baik secara intensifikasi ataupun ekstensifikasi. Rendahnya produktivitas padi diduga akibat rendahnya pengetahuan petani terhadap pengelolaan lingkungan tumbuh yang meliputi pemilihan varietas, penerapan teknologi budidaya berkelanjutan, dan lingkungan tumbuh spesifik wilayah. Penggunaan varietas yang dilepas mendominasi areal pertanaman padi di Indonesia hamper mencapai 90\% (Balibangtan, 2012). Penggunaan varietas atau kultivar lokal masih dikembangkan karena memiliki keunggulan karakter yang toleran terhadap berbagai cekaman lingkungan, aromatik, rasa, penampilan, atau sifat fisik beras spesifik (Wahyuti, 2012).

Kabupaten Poso di Sulawesi Tengah memiliki keragaman kultivar lokal yang tinggi yang belum terdaftar berdasarkan data Balitbangtan (2016), hal ini disebabkan karena masih kurangnya data hasil penelitian padi dari daerah Poso. Data primer hasil eksplorasi Tampoma tahun 2017, menunjukkan bahwa produktivitas kultivar padi sawah masih rendah rata-rata 3,73 ton/ha, dibawah produktivitas padi unggul baru. Kultivar lokal memegang peranan penting dalam mendukung ketahanan pangan nasional. Kultivar lokal memiliki banyak keunggulan karena bersifat spesifik lokasi bisa dipakai sebagai donor gen dalam pengembangan varietas unggul baru.

Tanaman padi yang digenangi sebagai padi sawah dan sebagai padi gogo ataupun sebagai padi huma memiliki potensi hasil yang berbeda. Hasil rata-rata padi sawah adalah 6-10 ton/ha, sementara padi gogo 2-5 ton/ha (Balitbangtan, 2016). Menurut Abdulrahman (2009), tanaman padi yang mengalami kondisi tidak tergenang dalam fase tertentu,secara berselang akan memperoleh banyak manfaat antara lain oksigen yang cukup tersedia sehingga bermanfaat terhadap ketersediaan hara (N,P,K dan $\mathrm{Si})$, kehidupan mikroorganisme aerob, serta meningkatkan ketahanan terhadap hama dan penyakit. Pada kondisi kekurangan air, tanaman padi akan melakukan adaptasi (drought avoidance) berupa pengurangan jumlah anakan, penggulungan daun dan mengurangi luas daun (Yoshida ,1981).

Saat ini salah satu hara yang hampir tidak pernah diberikan ke dalam tanah dalam pertanaman padi adalah silikon (Si), kondisi ini menyebabkan pertumbuhan dan hasil padi tidak optimal. Selama ini kebutuhan Si hanya mengandalkan pada ketersediaan Si di dalam tanah, yang belum tentu tersedia bagi tanaman. Padahal setiap kali panen, tanaman padi mengangkut Si sekitar 100-300 kg/ha, terbanyak diakumulasi pada jerami. Oleh karena itu, tanaman padi dan serealia lainnya dikenal sebagai tanaman akumulator Si. Menurut Yoshida (1985) menyatakan bahwa penyerapan $\mathrm{Si}$ terbesar adalah pada tanaman Gramineae termasuk padi, serapannya sekitar 10 kali N, 20 kali P, 6 kali K dan 30 kali Ca. Peran Si pada tanaman padi secara umum memperbaiki fungsi fisiologi tanaman, mempengaruhi massa jenis sel, serta meningkatkan kekuatan dan ketahanan sel. Silika membantu daun untuk lebih tegak, sehingga bisa meningkatkan tangkapan radiasi matahari sehingga fotosintesis bias meningkat sampai $10 \%$. Tanaman kekurangan Si mengakibatkan banyak kehilangan air karena transpirasinya tinggi, daun kurang dilindungi silika sehingga tanaman mudah kekeringan.

Upaya untuk mengatasi rendahnya produktivitas padi kultivar lokal Poso baik yang ditanam sebagai padi sawah ataupun padi gogo perlu dilakukan pemupukan Si sebagai hara yang banyak diserap padi. Pemberian Si dapat memperbaiki metabolisme tanaman sehingga bisa meningkatkan hasil dan kualitas hasil padi.

\section{Bahan dan Metode}

Percobaan dilaksanakan di Kebun Percobaan Fakultas Pertanian Universitas Padjadjaran Jatinangor, pada ketinggian tempat $700 \mathrm{~m}$ dpl. Waktu pelaksanaan percobaan dimulai bulan Agustus 2016 sampai dengan Januari 2017.

Bahan yang digunakan dalam penelitian ini adalah kultivar lokal asal Poso 36-Super dan Tagolu yang memiliki rasa pulen. Pupuk Silika Cair $\left(\mathrm{Si}(\mathrm{HO})_{4} 13,56 \%\right.$ per $\left.100 \mathrm{ml}\right)$; Pupuk urea $(46 \% \mathrm{~N}) 250 \mathrm{~kg} / \mathrm{ha}$; pupuk $\mathrm{KCl} \quad\left(36 \% \mathrm{P}_{2} \mathrm{O}_{5}\right) 50$ $\mathrm{kg} / \mathrm{ha}$ dan pupuk SP-36 $\left(60 \% \mathrm{~K}_{2} \mathrm{O}\right) 75 \mathrm{~kg} / \mathrm{ha}$. Alat yang digunakan adalah pot ember plastik berukuran diameter $30 \mathrm{~cm}$, baki persemaian $30 \mathrm{x}$ $20 \mathrm{~cm}$; timbangan analitik; jangka sorong, busur derajat, dan alat ukur pita. 
Rancangan percobaan yang digunakan dalam penelitian ini adalah Rancangan PetakPetak Terbagi (RPPT) yang disusun dalam rancangan acak kelompok dengan tiga faktor. Sebagai petak utama adalah 20 kultivar Lokal Poso yaitu $K_{1}=$ kultivar 36-Super dan $K_{2}$ =kultivar Tagolu. Sebagai anak petak terdiri dari kondisi genangan yaitu $\mathrm{G}_{0}=$ tanpa digenangi dan $\mathrm{G}_{1}=$ tanam macak-macak, digenangi setinggi $2-5 \mathrm{~cm}$ sejak umur padi 20 hari setelah tanam (hst) dan dibiarkan sampai 5 hari, dilakukan berselang 6 hari sampai padi berbunga. Pada fase keluar bunga hingga 10 hari sebelum panen digenangi setinggi $5 \mathrm{~cm}$, selanjutnya dikeringkan sampai panen. Sebagai anak-anak petak adalah 4 taraf pupuk silica, yaitu $S_{0}=$ tanpa silika; $S_{1}=0,5 \mathrm{~L}$ silika cair $/$ ha; $S_{2}=1,0 \mathrm{~L}$ silika cair/ha; $S_{3}=1,5$ silika cair $/$ ha. Terdapat 16 petak perlakuan, diulang tiga kali. Peubah yang diamati adalah komponen hasil (jumlah malai/rumpun, panjang malai, jumlah gabah/malai, bobot gabah/rumpun, bobot 1000 butir, dan Indeks panen) dan kualitas hasil (panjang gabah, lebar gabah, tebal gabah, dan persentase gabah isi).

Data dianalisis dengan sidik ragam pada taraf 5\%, menggunakan SPSS versi 17.0, uji nilai beda 2 rata-rata dengan uji jarak berganda Duncan pada taraf $5 \%$.

\section{Hasil dan Pembahasan}

Hasil pada tanaman padi didukung oleh variabel komponen hasil yaitu jumlah malai per rumpun, panjang malai, jumlah gabah per malai, bobot gabah per rumpun, bobot 1000 butir, dan indeks panen. Jumlah malai per rumpun menunjukkan bahwa kultivar 36-Super memiliki jumlah malai lebih tinggi sebesar 26,67 per rumpun dibandingkan dengan kultivar tagolu. Panjang malai kultivar Tagolu lebih panjangdaripada kultivar 36-Super dengan panjang malai $27,33 \mathrm{~cm}$, namun kedua kultivar memiliki kepadatan malai yang hampir sama, menempati sekitar 6 butir malai $/ \mathrm{cm}$. Karakteristik suatu tanaman padi yang ideal adalah tipe tanaman padi yang memiliki bobot malai yang berat sehingga bisa memiliki sink besar dan source cukup yaitu dengan jumlah malai efektif per rumpun adalah 12-15 malai, dan jumlah gabah 180- 240 (Jun dkk., 2003; Jun dkk., 2006). Malai yang besar dengan jumlah gabah per malai lebih banyak akan meningkatkan kepadatan malai (Zhang dkk., 2010). Ukuran panjang malai menurut Makarim dan Suhartatik (2009) dibedakan menjadi tiga ukuran, yaitu ukuran pendek $(<20 \mathrm{~cm})$, ukuran sedang $(20-30 \mathrm{~cm})$, dan ukuran panjang $(>30$ $\mathrm{cm})$. Hal ini menunjukkan bahwa varietas yang dipakai dalam percobaan ini adalah kelompok malai sedang.

Tabel 1 menunjukkan bahwa jumlah malai per rumpun dengan perlakuan digenangi lebih banyak malainya $(21,83)$ dan berbeda nyata dengan yang tidak digenangi yaitu sebagai padi gogo $(18,72)$. Dalam kondisi air yang cukup, maka proses fotosintesis dan penyerapan unsur hara dari akar dapat berjalan dengan baik. Menurut Vergara (1995), dalam kondisi tanaman kekurangan air pada stadia generatif akan menyebabkan berkurangnya jumlah malai. Perlakuan digenangi berselang (intermitten) menghasilkan panjang malai lebih tinggi dibandingkan dengan perlakuan tanpa genangan. Menurut Wang et.al.,, 2002) menyatakan bahwa dalam kondisi kekurangan air akan menghambat perkembangan malai. Dari analisis sidik ragam juga tidak menunjukkan efek interaksi antara ketiga perlakuan tersebut.

Tabel 1. Respons jumlah malai per rumpun dan panjang malai padi (Oryza sativa L.) kultivar lokal Poso.

\begin{tabular}{lccc}
\hline \multicolumn{1}{c}{ Perlakuan } & $\begin{array}{c}\text { Jumlah } \\
\text { malai per } \\
\text { rumpun }\end{array}$ & $\begin{array}{c}\text { Panjang } \\
\text { malai }(\mathrm{cm})\end{array}$ & $\begin{array}{c}\text { Jumlah } \\
\text { gabah per } \\
\text { malai } \\
\text { (butir) }\end{array}$ \\
\hline $\begin{array}{l}\text { Petak utama } \\
\text { Kultivar 36- }\end{array}$ & $26,67 \mathrm{a}$ & $21,15 \mathrm{~b}$ & $132,17 \mathrm{~b}$ \\
$\begin{array}{l}\text { Super } \\
\text { Kultivar Tagolu }\end{array}$ & $13,89 \mathrm{~b}$ & $27,33 \mathrm{a}$ & $164,69 \mathrm{a}$ \\
\hline $\begin{array}{l}\text { Anak Petak } \\
\text { Tanpa genangan }\end{array}$ & $18,72 \mathrm{~b}$ & $23,33 \mathrm{a}$ & $135,83 \mathrm{~b}$ \\
Digenangi & $21,83 \mathrm{a}$ & $25,14 \mathrm{a}$ & $161,04 \mathrm{a}$ \\
\hline $\begin{array}{l}\text { Anak-anak Petak } \\
\text { Tanpa silika }\end{array}$ & $18,81 \mathrm{a}$ & $23,47 \mathrm{a}$ & $136,53 \mathrm{a}$ \\
$\begin{array}{l}\text { Dosis silika 0,5 } \\
\text { L/ha }\end{array}$ & $20,13 \mathrm{a}$ & $24,42 \mathrm{a}$ & $142,75 \mathrm{a}$ \\
$\begin{array}{l}\text { Dosis silika 1 } \\
\text { L/ha }\end{array}$ & $21,56 \mathrm{a}$ & $24,19 \mathrm{a}$ & $164,18 \mathrm{a}$ \\
$\begin{array}{l}\text { Dosis silika 1,5 } \\
\text { L/ha }\end{array}$ & $20,60 \mathrm{a}$ & $24,87 \mathrm{a}$ & $150,28 \mathrm{a}$ \\
\hline Keterangan: angka & & & \\
\hline
\end{tabular}

Keterangan: angka yang diikuti huruf yang sama pada kolom yang sama tidak berbeda nyata

berdasarkan uji jarak berganda Duncan taraf 5\%

Jumlah malai akibat pemberian pupuk cair silika tidak berpengaruh nyata, namun dosis 1 
L/ha menghasilkan jumlah malai 21,56 malai/rumpun dan panjang malai 24,1 dengan jumlah $9 \mathrm{~cm}$ lebih tinggi dibandingkan dosis lainnya. Hasil penelitian Wei et.al.( 2009) menunjukkan hal yang sama, bahwa pemberian $\mathrm{Si}$ dengan konsentrasi 500 ppm, dapat meningkatkan komponen hasil seperti jumlah malai, jumlah gabah/malai dan persentase gabah isi. Meningkatnya hasil dengan dengan pupuk Silika menyebabkan posisi daun tegak sehingga fotosintesis bisa optimal.

Tabel 2. Respons bobot gabah per rumpun, bobot 1000 butir, dan indeks panen padi kultivar lokal Poso.

\begin{tabular}{lccc}
\hline \multicolumn{1}{c}{ Perlakuan } & $\begin{array}{c}\text { Bobot gabah } \\
\text { per rumpun } \\
(\mathrm{g})\end{array}$ & $\begin{array}{c}\text { Bobot } 1000 \\
\text { butir }(\mathrm{g})\end{array}$ & $\begin{array}{c}\text { Indeks } \\
\text { Panen }\end{array}$ \\
\hline $\begin{array}{l}\text { Petak utama } \\
\text { Kultivar 36- } \\
\text { Super }\end{array}$ & $56,68 \mathrm{a}$ & $21,50 \mathrm{a}$ & $0,25 \mathrm{a}$ \\
$\begin{array}{l}\text { Kultivar } \\
\text { Tagolu }\end{array}$ & $52,34 \mathrm{a}$ & $22,19 \mathrm{a}$ & $0,22 \mathrm{a}$ \\
$\begin{array}{l}\text { Anak Petak } \\
\text { Tanpa } \\
\text { genangan }\end{array}$ & $53,99 \mathrm{a}$ & $21,74 \mathrm{a}$ & $0,25 \mathrm{a}$ \\
$\begin{array}{l}\text { Digenangi } \\
\text { Anak-anak }\end{array}$ & $55,03 \mathrm{a}$ & $21,95 \mathrm{a}$ & $0,23 \mathrm{a}$ \\
$\begin{array}{l}\text { Petak } \\
\text { Tanpa silika }\end{array}$ & $50,46 \mathrm{a}$ & $21,38 \mathrm{~b}$ & $0,22 \mathrm{a}$ \\
$\begin{array}{l}\text { Dosis silika 0,5 } \\
\text { L/ha }\end{array}$ & $54,35 \mathrm{a}$ & $21,66 \mathrm{~b}$ & $0,22 \mathrm{a}$ \\
$\begin{array}{l}\text { Dosis silika 1 } \\
\text { L/ha }\end{array}$ & $57,77 \mathrm{a}$ & $22,48 \mathrm{a}$ & $0,24 \mathrm{a}$ \\
$\begin{array}{l}\text { Dosis silika 1,5 } \\
\text { L/ha }\end{array}$ & $55,47 \mathrm{a}$ & $21,86 \mathrm{~b}$ & $0,22 \mathrm{a}$ \\
\hline Keterangan: angka yang dilkuti & & \\
\hline
\end{tabular}

Keterangan: angka yang diikuti huruf yang sama pada kolom yang sama tidak berbeda nyata berdasarkan uji jarak berganda Duncan taraf 5\%

Jumlah gabah per malai kultivar Tagolu lebih banyak (164,69 gabah) dan berbeda nyata dengan kultivar 36-Super (132,17 gabah ). Tanaman yang memiliki kriteria hasil yang tinggi adalah tanaman yang menghasilkan jumlah malai 330 malai per $\mathrm{m}^{2}$ dan jumlah gabah 150 per malai (Peng dan Kush, 2003). Namun menurut Abdulah dkk. (2008), kriteria hasil padi yang tinggi adalah malainya berjumlah 12-18 per rumpun dan jumlah gabah per malai 150-250 butir. Hal ini sejalan dengan perlakuan digenangi menghasilkan panjang malai lebih tinggi. Pada kondisi kekurangan air, akan terjadi pemandulan tepung sari sehingga akan menurunkan pembentukan biji (Vergara 1995).
Perlakuan penggenangan berkala (sistem sawah) menghasilkan jumlah gabah per malai lebih banyak (161,04 butir) dan berbeda nyata dengan tanpa genangan atau sebagai padi gogo (135,83 butir). Menurut Setiobudi dkk. (2008) menyatakan bahwa jumlah gabah dipengaruhi oleh panjang gabah, cabang malai, dan pengisian bulir.

Hasil sidik ragam berdasarkan uji $\mathrm{F}$ pada Tabel 2 menunjukkan bahwa bobot gabah per rumpun, bobot 1000 butir, dan Indeks panen tidak berbeda nyata, dan juga tidak terjadi efek interaksi dari ketiga perlakuan tsb. Pengaruh yang berbeda nyata terjadi akibat perlakuan pupuk silika hanya terhadap bobot 1000 butir.

Dari Tabel 2 di atas, ternyata hasil peneltian menunjukkan bahwa bobot gabah per rumpun, bobot 1000 butir, dan indeks panen tidak mencapai produktivitas yang optimal. Perlakuan dosis silika menghasilkan indeks panen dan bobot gabah per rumpun yang tidak berbeda nyata dengan dengan dosis lainnya, sedangkan terhadap bobot 1000 butir berbeda nyata dengan dosis lainnya, pada dosis $1 \mathrm{~L} / \mathrm{ha}$. Tipe ideal tanaman padi dengan potensi hasil yang tinggi adalah yang menghasilkan bobot gabah 5 g per malai atau setara 60-75 g per rumpun, bobot 1000 butir adalah 28-30 g dan nilai Indeks Panen 50\% atau 0,55 (Peng dan Kush, 2003; Jun dkk.,; Yuan 2001). Perkembangan fase generatif pada tanaman umumnya didukung oleh pertumbuhan vegetatif (Arsyad, 2001). Namun demikian, menurut Takahashi (1995) pemberian silika pada tanaman padi dapat meningkatkan jumlah gabah per malai dan bobot gabah per rumpun. Peningkatan potensi hasil dapat dilakukan dengan meningkatkan produksi biomasa total dan indeks panen (Yoshida ,1981; Gardner, 1991; Kush, 1999). Peningkatan indeks panen dapat dilakukan dengan peningkatan ukuran sink, sedangkan biomasa dapat dilakukan dengan manipulasi genetic dan teknologi budidaya (Kush, 1999).

Sifat fisik gabah diamati dengan pengukuran panjang gabah, lebar gabah, tebal gabah dan persentase gabah isi. Hasil sidik ragam, dengan uji $\mathrm{F} 5 \%$, pada Tabel 3 menunjukkan pengaruh kultivar tidak berbeda nyata terhadap variabel sifat fisik, demikian pula pengaruh genangan, kecuali terhadap lebar gabah, tanpa genangan sebagai padi gogo lebih lebar daripada yang ditanam sebagai padi sawah. Pemberian pupuk silika berpengaruh 
terhadap sifat fisik gabah, kecuali terhadap persentase gabah isi.

Data sifat fisik menunjukkan bahwa panjang gabah kultivar 36-Super dan Tagolu tergolong sangat panjang $(7,5 \mathrm{~mm})$. Lebar gabah pada perlakuan digenangi lebih besar $(2,38 \mathrm{~mm})$ dan berbeda nyata dengan padi gogo. Perlakuan pupuk silika menghasilkan panjang gabah $(8,32)$, lebar gabah $(2,40 \mathrm{~mm})$, dan tebal gabah $(1,73 \mathrm{~mm})$ adalah lebih besar dan berbeda nyata dengan perlakuan tanpa silika dan dosis $0,5 \mathrm{~L} / \mathrm{ha}$, namun tidak berbeda nyata dengan dosis $1,5 \mathrm{~L} /$ ha.

Tabel 3. Respons panjang gabah, lebar gabah, tebal gabah, dan persentase gabah isi padi kultivar lokal Poso.

\begin{tabular}{lcccc}
\hline Perlakuan & $\begin{array}{c}\text { Panjang } \\
\text { gabah } \\
(\mathrm{mm})\end{array}$ & $\begin{array}{c}\text { Lebar } \\
\text { gabah } \\
(\mathrm{mm})\end{array}$ & $\begin{array}{c}\text { Tebal } \\
\text { gabah } \\
(\mathrm{mm})\end{array}$ & $\begin{array}{c}\text { Persentase } \\
\text { gabah isi } \\
(\%)\end{array}$ \\
\hline $\begin{array}{l}\text { Petak utama } \\
\text { Kultivar 36- }\end{array}$ & $8,07 \mathrm{a}$ & $2,40 \mathrm{a}$ & $1,66 \mathrm{a}$ & $80,46 \mathrm{a}$ \\
$\begin{array}{l}\text { Super } \\
\text { Kultivar }\end{array}$ & $8,32 \mathrm{a}$ & $2,33 \mathrm{a}$ & $1,69 \mathrm{a}$ & $84,88 \mathrm{a}$ \\
Tagolu & & & & \\
\hline $\begin{array}{l}\text { Anak Petak } \\
\text { Tanpa }\end{array}$ & $8,14 \mathrm{a}$ & $2,36 \mathrm{~b}$ & $1,65 \mathrm{a}$ & $81,11 \mathrm{a}$ \\
$\begin{array}{l}\text { genangan } \\
\text { Digenangi }\end{array}$ & $8,25 \mathrm{a}$ & $2,38 \mathrm{a}$ & $1,71 \mathrm{a}$ & $84,23 \mathrm{a}$ \\
\hline $\begin{array}{l}\text { Anak-anak } \\
\text { Petak }\end{array}$ & & & & \\
Tanpa silika & $8,13 \mathrm{~b}$ & $2,33 \mathrm{c}$ & $1,64 \mathrm{~b}$ & $82,36 \mathrm{a}$ \\
$\begin{array}{l}\text { Dosis silika } \\
\text { 0,5 L/ha }\end{array}$ & $8,15 \mathrm{~b}$ & $2,36 \mathrm{bc}$ & $1,67 \mathrm{~b}$ & $82,79 \mathrm{a}$ \\
$\begin{array}{l}\text { Dosis silika 1 } \\
\text { L/ha }\end{array}$ & $8,32 \mathrm{a}$ & $2,40 \mathrm{a}$ & $1,73 \mathrm{a}$ & $81,46 \mathrm{a}$ \\
$\begin{array}{l}\text { Dosis silika } \\
\text { 1,5 L/ha }\end{array}$ & $8,18 \mathrm{ab}$ & $2,39 \mathrm{ab}$ & $1,68 \mathrm{ab}$ & $84,06 \mathrm{a}$ \\
\hline $\begin{array}{l}\text { Keterangan: angka yang diikuti huruf yang sama } \\
\text { pada kolom yang sama tidak berbeda nyata } \\
\text { berdasarkan uji jarak berganda Duncan taraf 5\% }\end{array}$
\end{tabular}

Besar kecilnya persentase gabah isi dan gabah hampa dipengaruhi oleh besarnya laju asimilasi bersih, akumulasi bobot kering tanaman sebelum pembungaan, serta translokasi karbohidrat dari organ vegetatif ke malai selama periode pengisian biji (Wang et all., 2002). Tanaman padi dengan potensi hasil yang tinggi ditandai dengan persentase gabah isi $>$ 85\% (Abdulah dkk., 2008; Jun et al., 2006). Besarnya bobot kering tanaman mengindikasikan pertumbuhan optimal. Peningkatan laju fotosintesis pada fase generatif yang didukung tegaknya daun bendera menyebabkan penyerapan radiasi matahari dan fotosintesis tinggi, sehingga menghasilkan asimilat yang tinggi yang akan didistribusikan ke sink secara maksimal. Selain itu, Si juga akan memacu penyerapan fosfat sebagai sumber energi untuk fotosintesis.

\section{Kesimpulan dan Saran}

Kultivar 36-Super menghasilkan jumlah malai per rumpun lebih tinggi, sedangkan kultivar Tagolu menghasilkan malai lebih panjang. Perlakuan penggenangan berpengaruh terhadap jumlah malai per rumpun daripada tanpa penggenangan. Pemberian pupuk silika $1 \mathrm{~L} / \mathrm{ha}$ berpengaruh terhadap bobot gabah per rumpun, bobot 1000 butir, panjang gabah, lebar gabah dan tebal gabah. Tidak terdapat efek interaksi dari ketiga perlakuan. Pupuk silika cair seyogyanya diberikan lebih dari satu kali untuk meningkatkan komponen hasil dan kualitas hasil .

\section{Daftar Pustaka}

Abdullah, B.; Tjokrowidjojo, S. dan Sularjo. 2008. Perkembangan dan Prospek Perakitan Padi Tipe Baru di Indonesia. J. Litbang . J. Litbang Pertanian 27 (1):1-9

Arsyad, A.R. 2001. Pengaruh Olah Tanah Konservasi dan Pola Tanam Terhadap Sifat Fisika Tanah Ultisol dan Hasil Jagung. Jurnal Agronomi. 8(2):111-116.

Balitbangtan (Badan Penelitian dan Pengembangan Pertanian). 2016. Deskripsi Varietas Unggul Padi. Departemen Pertanian. Jakarta.

Gardner, P.F., Pearce, B.R. dan Mitchel. 1991. Fisiologi Tanaman BUdidaya. Universitas Indonesia . Jakarta.

Jun, M.A, Wen-bo MA, Ming DF.,Yang SM., Zhu QS. 2006. Characteristics of rice plant with heavy panicle. Agricultural sciences in China 5(12):911-918.

Khan hush, Gs.,1999. New Plant Type of Rice for Increasing Genetic Yield Potential. In: Nanda Js., Editor. Rice Inc. and Genetics. Science Publishers. USA p 99-108.

Makarim, A.K dan Suhartatik, E. 2009. Morfologi dan Fisiologi Tanaman Padi. Publikasi Balai Besar Penelitian Tanaman Padi. Hal:295-329. 
Peng, S., and Khush G.S. 2003. Four Decade of Breedingfor Varietal Improvement of Irrigated Lowland Rice in The International Rice Research Institute. Plant Prod. Sc. 6:157-164.

Setiobudi, D., B. Abdulah, H. Sembiring, dan L.P. Wardana. 2008. Penngkatan Hasil Padi Tipe Baru. Melalui Pengelolaan Hara Pupuk Nitrogen. Prosiding Simposium V Tanaman Pangan - Inovasi Teknologi Tanaman Pangan. Pusat Penelitian dan Pengembangan Tanaman Pangan. Badan Penelitian dan Pengembangan Pertanian vol 2: 345-353.. 1995. Uptake and Physiological Fucntion of Silica. P. 420433. In Matsuo, T.K Kumazawa, R. Ishii, K.Ishihara, and H. Hirata (eds). Science of Rice Plant. Volume Two. Physiology ,Food and Agriculture TResearch Center. Tokyo.

Tampoma, Wan Priando. 2017. Respons Karak-ter Morfofiosiologi, Hasil dan Sifat Fisik Gabah Padi Kultivar Lokal Poso Terhadap Pemupukan Silika Dan Kondisi Genangan. Disertasi. Pasca Sarjana Fakultas Pertanian Universitas Padjadjaran. Bandung.

Vergara, B.S. 1995. Bercocok Tanam Padi. Program Nasional PHT Pusat. Departemen Pertanian. Jakarta.
Wahyuti, T.B. 2012. Hubungan Karakter Agronomi dan Fisiologi de Japonica of ngan Hasil dan Upaya Meningkatkan Hasil Padi Varietas Unggul. Disertasi. Institut Pertanian Bogor.

Wang, X., Tao, L., Yu M. and Huang, X. 2002. Physiological Characteristics of "Super" Hybrid Rice Variety. Xieoyou9308. Chin. Journal. Rice Science. 16: 38-44.

Wei C. Zhang Y, Guo J, Han Y, Yuan J. 2009. Effect of Silica nanopartcles on growth and photosynthetic pigment contents of Scenedesmus obloquus. Journal of Environmental Sciences. 2010. 22(1) 155 160.

Yoshida, S. 1985. The Physiology Of Silicon in Rice. Ffic- Aspac. Techen. Bult. 25:1 -27.

Yuan L. 2001. Breeding of Super Hybrid Rice. In :Peng S., Hardy B. (Eds). Rice Research For Food Security and Poverty Alleviation. International Rice Research Institute. Los Banos, Philippines. Pp. 143149.

Zhang, H., Tan, G.I., Xue,Yg., Liu, I.J and Yang, J.C. 2010. Changes In Grain Yield and Morphological and Physiological Characteristics During 60- Year Evolution Japonica Rice Cultivars in Jiangsu. Acta Agron Sin. 3 (1) : 133 - 140. 